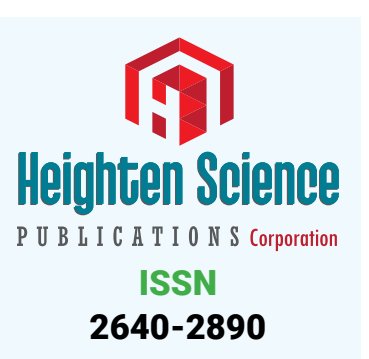

*Address for Correspondence: Maryam Asgharnia, Reproductive Health Research Center, Department of Obstetrics \& Gynecology, Al-Zahra Hospital, Medical School, Guilan University of Medical Sciences, Rasht, Iran,

Tel: +981333369224; +989111310019;

Email: h_fertility@gums.ac.ir;

maryamasgharnia@yahoo.com

Submitted: 15 June 2019

Approved: 01 July 2019

Published: 02 July 2019

Copyright: () 2019 Asgharnia M, et al. This is an open access article distributed under the Creative Commons Attribution License which permits unrestricted use, distribution, and reproduction in any medium, provided the original work is properly cited

Keywords: Measentric cyst; Case report

Check for updates
Case Report

\section{Mesenteric cysts: A rare case}

\section{Maryam Asgharnia ${ }^{1 *}$, Tayebeh Rahbar $^{2}$ and Seyedeh Fatemeh Dalil Heirati ${ }^{3}$}

\begin{abstract}
1Professor of Obstetric \& Gynecology, Reproductive Health Research Center, Department of Obstetrics \& Gynecology, Al-zahra Hospital, School of Medicine, Guilan University of Medical Sciences, Rasht, Iran

${ }^{2}$ Departments of Midwifery, Islamic Azad University, Rasht Branch, Rasht, Iran

${ }^{3} \mathrm{MSc}$ of Midwifery, candidate, Reproductive Health Research Center, Department of Obstetrics \& Gynecology, Al-zahra Hospital, School of Medicine, Guilan University of Medical Sciences, Rasht, Iran
\end{abstract}

\section{Abstract}

Mesenteric cysts are rare benign intra-abdominal tumors with an incidence of 1 case per 250,000 hospital admission. This lesion occurs most frequently in women in the reproductive period.The etiology of such cysts remains unknown but several theories regarding their development exist. Most of these lesions present with vague abdominal pain and nausea. Less commonly they will present with bowel obstruction due to external compression. The diagnosis of these tumors is by abdominal ultrasound or computed tomography. We report a case of Mesenteric cyst in 51-year-old female patient.

\section{Introduction}

Mesenteric cysts are rare benign intra-abdominal tumors with an incidence of 1 case per 250,000 hospital admission. The etiology of such cysts remains unknown but several theories regarding their development exist [1]. Mesenteric cyst on the basis of internal content is divided into two categories, lymphatic and serous [2].

These lesions can present with symptoms such as abdominal pain, nausea, vomiting, anorexia, and a change in bowel habits, however, most commonly they are asymptomatic, and detected incidentally via physical exam, or imaging. Although most mesenteric cysts are benign, these lesions do occasionally cause complications, including intestinal obstruction, volvulus, torsion, or even hemorrhagic shock secondary to bleeding or rupture [3].

Complete surgical excision of the cyst is the treatment of choice. Due to the rarity of this entity and the lack of specific symptoms, correct pre-operative diagnosis is difficult. Knowledge of these lesions is important due to the various complications associated with suboptimal surgical management [1].

\section{Case report}

51-year-old woman with an intense and heaviness in the abdomen and abnormal vaginal bleeding was admitted for cystectomy by Gynecologist. Patient had recorded Irregular vaginal bleeding from a year ago, which was under diagnostic curettage 7 months ago. Pathological findings were reported endometrial polyps and endocervicitis but bleeding, pain and abdominal distention not resolved. 
Ultrasound revealed uterine size $50 \times 86$ and retroverted with heterogeneous echo of Adenomyosis. In the right upper part of the uterus was seen a multilocular cyst with contain internal echoes and parietal calcification in $65 \times 56$. Little liquid was found in the pelvic cavity. CT scan was recommended. Spiral CT scan showed a multilocular cyst in $60 \times 67$ with parietal calcification in supra pubic region which it was separated from ovaries. Para Ovarien cysts, dermoid cysts or enlarged lymph nodes and ascites were not seen. Liver, gallbladder, pancreas and spleen were normal.

Laparotomy was performed to remove an abdominal mass with hemoglobin: 12/8 G / DL, platelet: 268000, tumor markers: CEA=1/5, CA=10/5, CA125=100, normal coagulation factor and negative beta hcG. The abdomen was incised open according pfanstiehl incision. Uterus and ovaries were normal. White mass apparently fibromatosis with solid wall and sticking to the small intestine mesotheliuma that was removed slowly from the gut. Attachment sites were not bleeding. After checking, the layers of the abdominal closed.

After surgery, the patient was NPO for 24 hours. Vital signs were normal. Blood pressure: $120 / 80$, respiration 88 and temperature was $37^{\circ}$ C. Patients with oral cefixime and metronidazole was discharged 3 days after surgery. Surgical pathology was reported fibrohyalinized tissue with lymphangiectasis (Figure 1), calcification (Figure 2), cholesterol cleft formation (Figure 3).

\section{Discussion}

Benign abdominal cystic tumors are rare. They include retroperitoneal, mesenteric, and omental cysts [4], Benign multicystic peritoneal mesothelioma (BMPM), also

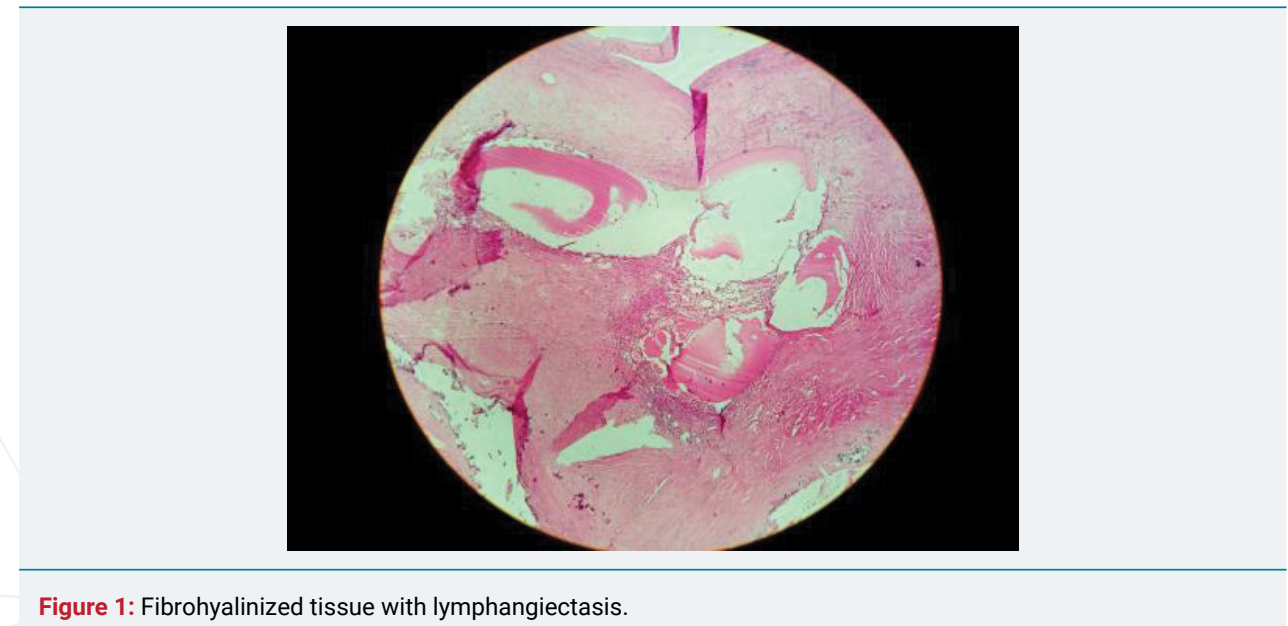

Figure 1: Fibrohyalinized tissue with lymphangiectasis.

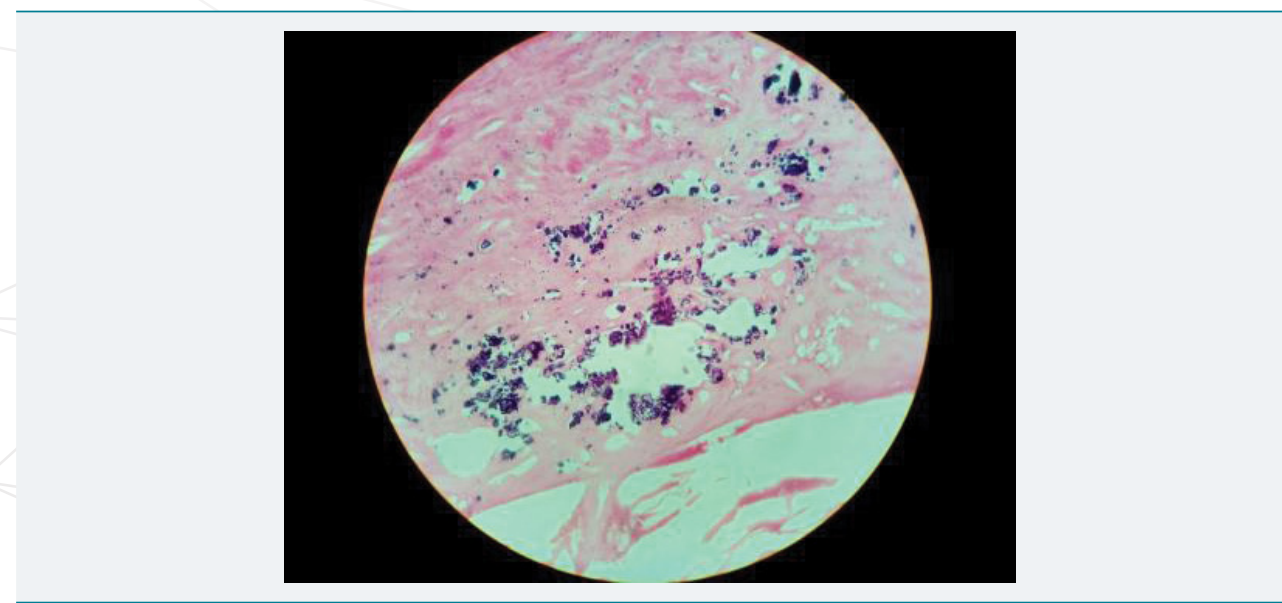

Figure 2: Calcification. 


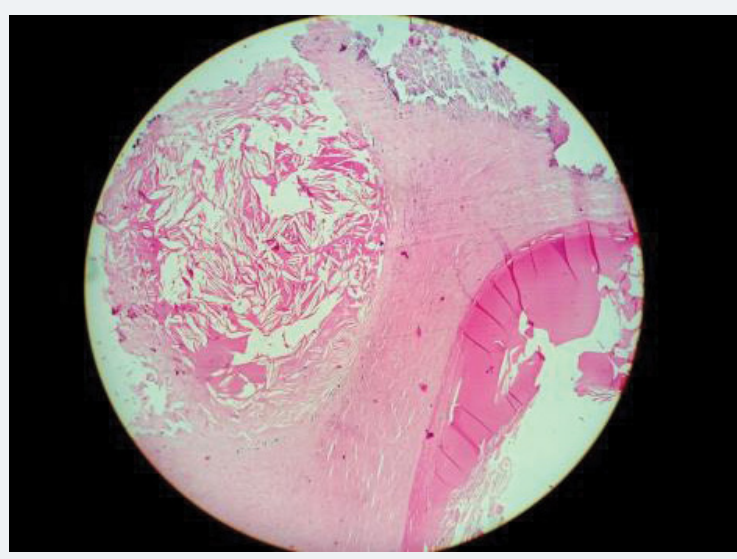

Figure 3: Cholesterol cleft formation.

known as multilocular peritoneal inclusion cysts, is an uncommon lesion arising from the peritoneal mesothelium that covers the serous cavity. The characteristic behavior of BMPM is benign; however, rare cases of malignant transformation have been noted [5-7].

This lesion occurs most frequently in women in the reproductive period [8]. The etiology of such cysts remains unknown but several theories regarding their development exist [1]. Mesenteric cysts have similar pathogenesis, but may have different histopathological origin and structure [9].

There are several classifications of these formations, among which the one based on histopathology features including 6 groups [10]. Most often they represent ectopic lymphatic tissue - lymphatic, chylous cysts [6]. In our case surgical pathology was reported fibrohyalinized tissue with lymphangiectasis, calcification, and cholesterol cleft formation.

The etiology remains unclear, but it is well known that many inciting factors may promote hyperplastic and neoplastic changes in mesothelial cells $[5,7,8,12]$.

Cystic lymphangioma mostly occurs in the first decade of life, with a female predominance. It is usually accompanied by acute abdominal symptomatology. Lymphatic cysts occur also show female predominance, and as a rule are asymptomatic $[13,14]$, but uzum et al. [8], revealed the most common presenting com plaints are pelvic and low abdominal pain but the lesions are sometimes incidental findings at laparatomy. The presence of a history of prior surgery is endometriosis and uterine leiomyoma. In our case the patient presented only recurrent heavy belly, abdominal distention and irregular vaginal bleeding. Most of these lesions present with vague abdominal pain and nausea. Less commonly they will present with bowel obstruction due to external compression. The diagnosis of these tumors is by abdominal ultrasound or computed tomography [4].

Because of variable and non-specific clinical symptoms and signs, they are discovered either accidentally during an abdominal radiological examination for other reason or during laparotomy for the management of one of the complications [1].

Preoperative diagnosis of MCs is difficult. Laboratory findings are usually within normal limits. The US of the abdomen reveals a hypoechogenic cystic mass with or without internal echos (diaphragms). The CT scan allows determining the size of the mass, sometimes the point of the origin, the relation to the neighboring organs and depicts better wall calcifications, however, does not highlight the correlation with the soft tissues [14]. 
In our ultrasound revealed uterine size $50 \times 86$ and retroverted with heterogeneous echo of Adenomyosis. In the right upper part of the uterus was seen a multilocular cyst with contain internal echoes and parietal calcification in $65 \times 56$. Little liquid was found in the pelvic cavity. CT scan was recommended. Spiral CT scan showed a multilocular cyst in $60 \times 67$ with parietal calcification in supra pubic region which it was separated from ovaries.

Complete surgical excision of the cyst is the treatment of choice (1-3-4) surgical excision is considered the mainstay for therapy, as recurrence of the cyst can occur with lesser procedures. It should be noted that with cysts that are adherent, it may be necessary to remove part of the mesentery with the mass [3].

\section{References}

1. Pithawa AK, Bansal AS, Kochar SPS. Mesenteric cyst: A rare intra-abdominal tumour. Med J Armed Forces India 2014; 70: 79-82. Ref.: https://bit.ly/2xr3B17

2. Yeganeh R, kazemy H. Mesenteric cyst: a case report with an unusual protests. Quarterly Lorestan University of Medical Sciences.1994; 16: 63-69.

3. Jain V, DeMuro JP, Geller M. A Case of Laparoscopic Mesenteric Cyst Excision. Case Reports in Surgery. 2012 2012: 3. Ref.: https://bit.ly/2xv7JNz

4. Mackenzie DJ, Shapiro SJ, Gordon LA. Laparoscopic Excision of a Mesenteric Cyst. Journal of Laparoendoscopic Surgery. 1993; 3: 295-299. Ref.: https://bit.ly/2RMPzAp

5. Safioleas MC, Constantinos K, Stamatakos M. Benign multicystic peritoneal mesothelioma: A case report and review of the literature. World J Gastroenterol. 2006; 21: 12: 5739-5742. Ref.: https://bit.ly/2YqSst7

6. Cavallaro A, Berretta M, Cavallaro V. Cystic Peritoneal Mesothelioma: Report of a Case. 2011; 41: 141-146. Ref.: https://bit.ly/2YtjgJc

7. Wang TB, Dai WG, Liu DW. Diagnosis and treatment of benign multicystic peritoneal mesothelioma. World $J$ Gastroenterol. 2013; 19: 6689-6692. Ref.: https://bit.ly/2KPgXNH

8. Uzüm N, Ozçay N, Ataoğlu O. Benign multicystic pertoneal mesothelioma. The Turkish Journal of Gastroenterology : the Official Journal of Turkish Society of Gastroenterology. 2009; 20: 138-141. Ref.: https://bit.ly/2FMd87I

9. Miljković D, Gmijović D, Radojković M. Mesenteric cyst Arch Oncol. 2007; 15: 91-93. Ref.: https://bit.ly/2J3BwUd

10. Huis M, Balija M, Lez C, Szerda F, Stulhofer M. Mesentric cysts. Acta Med Croatica. 2002; 56: 119-124. Ref.: https://bit.ly/2FJ3G4U

11. Justin AS, Carman R, Allison AA. Benign multicystic peritoneal mesothelioma: A rare case presenting as pneumoperitoneum and pneumotosis intestinalis. J Gastrointest Oncol. 2011; 2: 55-58. Ref.: https://bit.ly/2xqB2kq

12. Elbouhaddouti $H$, Bouassria A, Mouaqit A, El Bachir Benjelloun. Benign cystic mesothelioma of the peritoneum: a case report and literature review. World Journal of Emergency Surgery 2013; 8: 43. Ref.: https://bit.ly/305wDQ6

13. Huis M, Balija M, Lez C, Szerda F, Stulhofer M. Mesentric cysts. Acta Med Croatica. 2002; 56: 119-124. Ref.: https://bit.ly/2FJ3G4U

14. Falidas E, Mathioulakis S, Vlachos K. Traumatic mesenteric cyst after blunt abdominal trauma.International Journal of Surgery Case Reports. 2011; 159-162. Ref.: https://bit.ly/2XeFsFt 